\title{
A simplified physical model for assessing solar radiation over Brazil using GOES 8 visible imagery
}

\author{
Juan Carlos Ceballos, Marcus Jorge Bottino, and Jaidete Monteiro de Souza \\ Divisão de Satélites e Sistemas Ambientais, Centro de Previsão de Tempo e Estudos Climáticos, Instituto Nacional de \\ Pesquisas Espaciais, São Paulo, Brazil \\ Received 23 February 2003; revised 26 August 2003; accepted 15 October 2003; published 30 January 2004.
}

[1] Solar radiation assessment by satellite is constrained by physical limitations of imagery and by the accuracy of instantaneous local atmospheric parameters, suggesting that one should use simplified but physically consistent models for operational work. Such a model is presented for use with GOES 8 imagery applied to atmospheres with low aerosol optical depth. Fundamental satellite-derived parameters are reflectance and cloud cover. A classification method applied to a set of images shows that reflectance, usually defined as upper-threshold $R_{\max }$ in algorithms assessing cloud cover, would amount $\sim 0.465$, corresponding to the transition between a cumuliform and a stratiform cloud field. Ozone absorption is limited to the stratosphere. The model considers two spectral broadband intervals for tropospheric radiative transfer: ultraviolet and visible intervals are essentially nonabsorbing and can be processed as a single interval, while near-infrared intervals have negligible atmospheric scattering and very low cloud transmittance. Typical values of $\mathrm{CO}_{2}$ and $\mathrm{O}_{3}$ content and of precipitable water are considered. A comparison of daily values of modeled mean irradiance with data of three sites (in rural, urban industrial, and urban coastal environments), September-October 2002, exhibits a bias of $+5 \mathrm{~W} \mathrm{~m}^{-2}$ and a standard deviation of $\sim 15 \mathrm{~W} \mathrm{~m}^{-2}\left(0.4\right.$ and $1.3 \mathrm{MJ} \mathrm{m}^{-2}$ for daily irradiation). A comparison with monthly means from about 80 automatic weather stations (covering a large area throughout the Brazilian territory) still shows a bias generally within $\pm 10 \mathrm{~W} \mathrm{~m}^{-2}$ and a low standard deviation $\left(<20 \mathrm{~W} \mathrm{~m}^{-2}\right)$, but the bias has a trend in September-December 2002, suggesting an annual cycle of local $R_{\max }$ values. Systematic (mean) errors in partial cloud cover and in nearly clear-sky situations may be enhanced using regional values for atmospheric and surface parameters, such as precipitable water, $R_{\max }$, and ground reflectance. The larger errors are observed in situations of high aerosol load (especially in regions with industrial activity or forest or agricultural fires). The last case is evident when sites in the Amazonian region or São Paulo city are selected. When considering daily values averaged within $2.5^{\circ} \times 2.5^{\circ}$ cells, the standard error is lower than $20 \mathrm{~W} \mathrm{~m}^{-2}$; present results suggest an annual cycle of mean bias ranging from +10 to $-10 \mathrm{~W} \mathrm{~m}^{-2}$, with an amplitude of $\sim 10 \mathrm{~W} \mathrm{~m}^{-2}$. These values are close to the proposed requirements of $10 \mathrm{~W} \mathrm{~m}^{-2}$ for the mean deviation and $25 \mathrm{~W} \mathrm{~m}^{-2}$ for the standard deviation. It is expected that the introduction of a reference grid containing mean values of parameters within a cell could induce a decrease in the standard deviation of mean errors and the correction of their annual cycle. A model adaptation for assessing the effect of high aerosol loads is needed in order to extend improvements to the whole

Brazilian area. INDEX TERMS: 3360 Meteorology and Atmospheric Dynamics: Remote sensing; 3359 Meteorology and Atmospheric Dynamics: Radiative processes; 0360 Atmospheric Composition and Structure: Transmission and scattering of radiation; KEYWORDS: solar radiation, satellite, GOES 8, Brazil

Citation: Ceballos, J. C., M. J. Bottino, and J. M. de Souza (2004), A simplified physical model for assessing solar radiation over Brazil using GOES 8 visible imagery, J. Geophys. Res., 109, D02211, doi:10.1029/2003JD003531.

\section{Introduction}

[2] Monitoring of solar radiation at ground level is an important task because of its main role in a variety of natural phenomena such as surface radiation budgets and related

Copyright 2004 by the American Geophysical Union. 0148-0227/04/2003JD003531\$09.00 evapotranspiration, which affect human activities (for instance agriculture and solar energy use) and, ultimately, regional climate. Given the cost of instruments and maintenance of a dense network, geostationary satellite information appears as an interesting, useful tool because of the spatial resolution and time frequency of scanning of shortwave flux reflected by the earth-atmosphere system. This is especially 
noteworthy in countries like Brazil, which shows extended regions with a low-density population and difficult access. It is worthwhile to note that the Global Energy Balance Archive (GEBA), organized since 1985, contains pyranometric data on a global scale; however, Wild et al. [1995] do not report data over that country. As a matter of fact, only two Baseline Surface Radiation Network (BSRN) stations produce registered data over an area of about $8.4 \times 10^{6} \mathrm{~km}^{2}$. Although an automatic weather stations network exists that provides pyranometric data (see http://www4.cptec.inpe.br), large areas remain without information.

[3] Geostationary satellite data have been used for more than 20 years for assessing solar radiation by using empirical or semiempirical statistical approaches between emerging reflected radiance and "ground truth" furnished by pyranometers [Tarpley, 1979; Cano et al., 1986] or by establishing physical models that take explicit account of radiative transfer properties of earth-atmosphere components (e.g., Gautier et al. [1980] or Pinker and Ewing [1985] for GOES; Stuhlmann et al. [1990] for Meteosat; Nunes [1993] for GMS). Recent models take additional benefit from information provided by polar satellites like those of the NOAA series [Whitlock et al., 1995]. Some of them are being used operationally for solar radiation monitoring in some countries or for global climatological studies in the Global Energy and Water Cycle Experiment (GEWEX) program [Pinker et al., 2001; Stackhouse et al., 2001].

[4] Shortwave radiative transfer in the atmosphere is recognized as a complex phenomenon that can be described by numerical procedures, but the accuracy of flux assessment in real situations is affected by limited information about time and the spatial variability of some parameters (for instance, ground albedo, profile of water vapor content, or aerosol load are provided mainly by atmospheric circulation models or climatologies) as well as by somewhat undefined size, composition, and geometry of clouds. Also, some discrepancies between theory and observations of water vapor and cloud impact on absorption are still a subject of current discussion [Ramaswamy and Freidenreich, 1998; Pope et al., 2002]. Schmetz [1989] and Pinker et al. [1995] presented comprehensive analyses of physically based satellite methods and their limitations for surface irradiance assessment. They pointed out that different methods yielded irradiation errors of $\sim 10 \%$ for daily mean and $\sim 5 \%$ for monthly mean but were not better than $10 \mathrm{~W} \mathrm{~m}^{-2}$. Also, comparison with located surface stations is a delicate question; grouping surface data from the GEBA network within grid cells allows one to decrease the RMS error of differences between satellite-based and ground truth data from $27 \mathrm{~W} \mathrm{~m}^{-2}$ (single stations) to $15 \mathrm{~W}$ $\mathrm{m}^{-2}$ (grid cell average).

[5] Reported physical models exhibit various degrees of complexity. Considering those designed for operational purposes, they may use products of broadband transmittances (e.g., Staylor method, cited by Pinker et al. [1995]) or several spectral intervals and atmospheric layers [Pinker and Laszlo, 1992]. The latter defines an equivalent cloud layer within the atmosphere, deduced from observed reflectance, which, in turn, allow the assessment of the total atmospheric transmittance at ground level. Also, profit may be taken from previous theoretical results that suggest a nearly linear relationship between surface irradiance and planetary albedo [Schmetz, 1989, 1993]; this fact reduces the problem to the modeling of the local planetary albedo for extreme situations of clear sky and overcast sky as well as potential atmospheric absorption, complemented by a satellite assessment of cloud cover [Stuhlmann et al., 1990].

[6] Concerning the Brazilian region, Meteosat images have been used in models reported by Pereira et al. [1996] and Ceballos and Moura [1997]. Satellite nadir at $0^{\circ}$ longitude allows the proper cover of northeast Brazil, but far western Amazon and southern regions are observed with too-high satellite zenithal angles. The Meteosat pixel size is larger than $3 \mathrm{~km}$, and the visible (VIS) channel exhibits a somewhat wide spectral width; observed radiances are representative of planetary albedo but must be influenced by water vapor absorption bands and near-infrared ground reflectance. GOES-East (nadir at $75^{\circ} \mathrm{W}$ longitude) covers the whole country. The VIS channel presents a narrower spectral width and a higher spatial definition $(1-1.5 \mathrm{~km})$. On one hand, it does not provide information about reflectance or absorption in the near-infrared interval; on the other hand, local ground and cloud reflectances are nearly constant over the visible interval. Radiance emerging toward both Meteosat and GOES is partially attenuated by the ozone band in the visible spectrum.

[7] GOES 8 VIS channel characteristics allow us to define a model divided into only two broadband intervals (with a second-order correction for the UV interval) using a minimal set of simple but physically well-defined properties. We present a model whose basic ideas were developed in 1993 in a Meteosat context [Ceballos and Moura, 1997]. Two main data are basically extracted from the VIS channel: (1) global irradiance in the VIS spectrum and (2) cloudiness (which strongly controls fluctuations in near-infrared (NIR) irradiance). After adaptation for the GOES 8 context and further development at the Centro de Previsão de Tempo e Estudos Climaticos (CPTEC) [Ceballos et al., 1998], the present version (hereinafter labeled GL1.2, "GL" meaning "global radiation") improves former cloud cover assessments, includes water vapor, carbon dioxide, and ozone absorption, and corrects signal degradation for reflectance assessment in channel 1. In order to compare its results with Brazilian ground data, we adopt the prescribed conditions suggested by Whitlock et al. [1995] for the expected mean (bias of $<10 \mathrm{~W} \mathrm{~m}^{-2}$ ) and the standard deviation $\left(<25 \mathrm{~W} \mathrm{~m}^{-2}\right)$ for monthly means.

\section{GL1.2 Model Structure}

[8] Net flux at the top of the atmosphere (TOA) is not assessed by the model so that linear relationships like those verified with ground level irradiance [Schmetz, 1989, 1993] are not sought. The main feature of the ground level (GL) model is to use information from only one satellite (reflectance in VIS channel) for assessing solar flux in two different broadband intervals (visible and near-infrared), where physical characteristics of radiative transfer must be processed in quite different ways. Ultraviolet fluxes enter mainly as a second-order (but not negligible) term. Version GL1.2 does not include the presence of aerosol.

[9] The GOES 8 VIS (channel 1) spectral interval is $\Delta$ $(0.55-0.75 \mu \mathrm{m})$. Its response function $\varphi(\lambda)$ is such that the effective spectral interval (defined by $\varphi \geq 0.5$ ) is $\Delta_{\text {GOES }}$ $(0.52-0.72 \mu \mathrm{m})$. Ground and cloud reflectance are rather 
constant within the interval $\Delta_{\text {VIS }}(0.4-0.7 \mu \mathrm{m})$; thus reflectance measured in $\Delta_{\mathrm{GOES}}$ can be assumed as representative of the $\Delta_{\text {VIS }}$ interval. On the other hand, the VIS channel does not provide direct information about the transmittance of solar radiation in the UV and NIR intervals. Given this behavior, the GL1.2 considers three working intervals: UV in $\Delta_{\mathrm{UV}}(0.1-0.4 \mu \mathrm{m})$, VIS in $\Delta_{\mathrm{VIS}}(0.4-0.7 \mu \mathrm{m})$, and NIR in $\Delta_{\mathrm{NIR}}(0.7-2.8 \mu \mathrm{m})$.

[10] Satellite information is spectral radiance $L$ [Weinreb et al., 1997]. Reflectance factor $F$ and emerging irradiance $E_{\mathrm{VISGOES}}$ in the $\Delta_{\mathrm{GOES}}$ interval may be assessed by the expressions

$$
F=\frac{\pi L}{S_{\mathrm{GOES}}}, \quad E_{\mathrm{VIS}_{p}}=\frac{1}{f} \frac{F}{\mu_{o}}
$$

The quantity $f$ is a bidirectional reflectance function correcting the effects of anisotropic reflection [Lubin and Weber, 1995]. $S_{\mathrm{GOES}}$ is a mean spectral solar flux density at TOA included in the VIS sensor interval (corrected for SunEarth distance). Lubin and Weber [1995] parameterizations yield maximal values $f \approx 1.1-1.2$ in the case of stratiform (St) clouds with satellite lines-of-sight toward southern Brazil and a slanting solar beam. Yet, solar irradiance is low in such conditions. The case of cumuliform $(\mathrm{Cu})$ clouds could be different, but they are physically ill defined when observing one pixel. Consequently, $f=1$ is assumed in all cases.

[11] The VIS interval allows for $38.8 \%$ of the solar constant. The radiation balance of the earth-atmosphere system may be described by

$$
\mu_{o} S_{\mathrm{VIS}}=E_{\mathrm{VIS}_{p}}+A_{\mathrm{VIS}_{a}}+\left(1-R_{\mathrm{VIS}_{g}}\right) G_{\mathrm{VIS}} .
$$

Here, $\mu_{o}=\cos Z_{o}$ is the cosine of solar zenith angle $Z_{o}$, and $R_{\mathrm{VIS} g}$ is ground reflectance. Extraterrestrial irradiance (left term) is partitioned in a reflected irradiance $E_{\mathrm{VIS}_{p}}$ at TOA, an absorbed portion $A_{\mathrm{VIS}_{a}}$ within atmosphere, and irradiance absorbed by the ground. When aerosol effects and weak absorption by gases such as $\mathrm{NO}_{x}$ and $\mathrm{O}_{2}$ are neglected, Rayleigh scattering and weak absorption by Chappuis bands are the main processes affecting radiative transfer in clear-sky conditions. Scattering by clouds overwhelmingly dominates radiative processes in this interval. While their absorption properties and experimental measurements are still a matter of discussion [Valero et al., 2000], it will be accepted that clouds are essentially conservative within the VIS interval [Welch et al., 1980]. We shall assume that atmospheric absorption in the VIS interval is mainly due to stratospheric ozone.

[12] The UV interval allows for $8.0 \%$ of the solar constant [Iqbal, 1983]. Hartley band (hereinafter referred to as UV1) is highly absorbing in this interval, while Huggins band (hereinafter referred to as UV2), included in $\Delta_{\mathrm{UV} 2}(0.3-$ $0.4 \mu \mathrm{m}$ ), accounts for $7.5 \%$ of the solar constant and is only partially absorbing. A former version (GL1.1) neglected all the UV interval, but a systematic negative error was found in the model. An analysis of UV spectral absorption for the clear-sky atmosphere was performed using Santa Barbara DISORT Atmospheric Radiation Transfer (SBDART) [Ricchiazzi et al., 1998]. It was found that the contribution of UV1 to ground irradiance is actually negligible, as shown

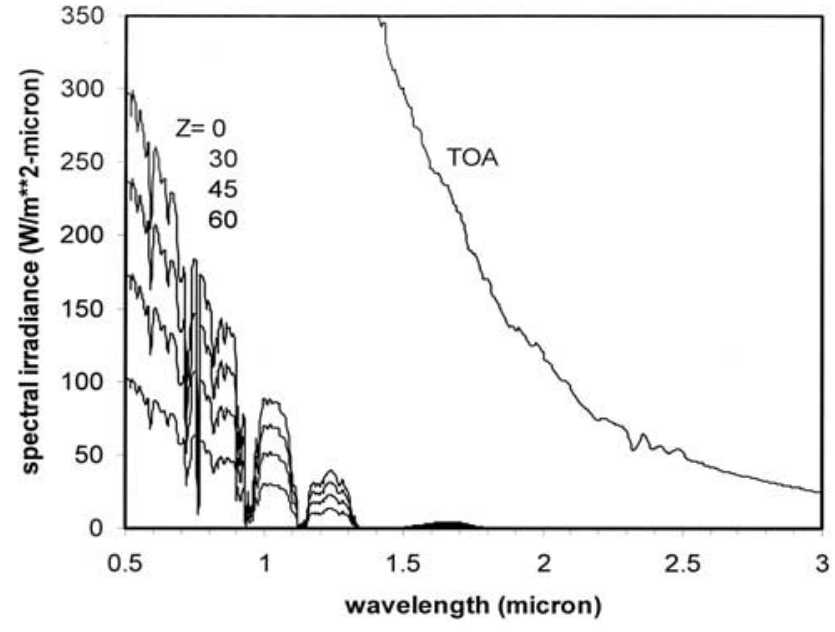

Figure 1. Spectral irradiance transmitted through a cloud with optical depth $\tau=64$ in the VIS spectrum, base at $2000 \mathrm{~m}$, imbedded in a tropical atmosphere. Four solar zenith angles $Z$ are considered. Also included is irradiance at normal incidence at TOA.

in section 3; therefore the GL1.2 version includes only UV2. Similarly to equation (2), atmospheric absorption will be attributed to ozone (assumed to be concentrated in the stratosphere) so that a simple radiation balance may be written, limited to the UV2 interval:

$$
\mu_{o} S_{\mathrm{UV} 2}=E_{\mathrm{UV} 2_{p}}+A_{\mathrm{UV} 2_{a}}+\left(1-R_{\mathrm{UV} 2_{g}}\right) G_{\mathrm{UV} 2} .
$$

[13] Radiation in the NIR interval extends over $50.8 \%$ of the solar spectrum, being mainly affected by absorption due to water $\left(\mathrm{H}_{2} \mathrm{O}\right)$ in a vapor and liquid phase and by carbon dioxide $\left(\mathrm{CO}_{2}\right)$. Given that the optical depth for Rayleigh scattering decreases rapidly with wavelength, it is assumed that only a direct beam exists in clear-sky conditions; on the other hand, if clouds cover a fractional area $C$ (cloudiness), we are lead to a simple expression for global irradiance $G_{\mathrm{NIR}}$ :

$$
G_{\mathrm{NIR}}=\left[(1-C) \mu_{o}\left(S_{\mathrm{NIR}}-\Delta S\right)+C \delta G\right] /\left(1-R_{\mathrm{NIR}_{g}} C R_{\mathrm{NIR}_{c}}\right),
$$

where $\Delta S=\Delta S\left(\mathrm{H}_{2} \mathrm{O}\right)+\Delta S\left(\mathrm{CO}_{2}\right)$ is flux density depleted from the TOA directional flux $S_{\mathrm{NIR}}$ by $\mathrm{H}_{2} \mathrm{O}$ (vapor) and $\mathrm{CO}_{2}$ atmospheric columns, and $\delta G$ is the NIR irradiance transmitted through a typical cloud. The term (1 $R_{\mathrm{NIR}_{\mathrm{g}}} C R_{\mathrm{NIR}_{c}}$ ) accounts for multiple reflections of NIR diffuse radiation between the ground and the cloud base $\left(R_{\mathrm{NIR}_{\mathrm{g}}}\right.$ and $R_{\mathrm{NIR}_{c}}$ are respective reflectances). Clouds show strong absorption and reflection in the NIR interval such that $\delta G$ is virtually constrained to conservative spectral intervals between absorption bands. Radiative transfer assessment makes it evident that conservative transmittance is low in moderately thick clouds. Figure 1 shows transmittance assessed by SBDART for a cloud imbedded in a model tropical atmosphere [McClatchey et al., 1971], with VIS optical thickness $\tau=64$, base at $2000 \mathrm{~m}$ height. According to the microphysics of fair weather $\mathrm{Cu}, \mathrm{St}$ (ocean), and St (land) clouds [Liou, 1992, Table 4.2], this value of $\tau$ corresponds to a geometrical thickness of $\sim 520,630$, and $435 \mathrm{~m}$, respectively. 


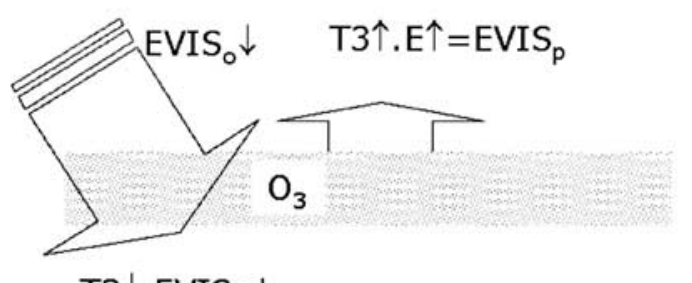

T3\.EVISo $\downarrow$

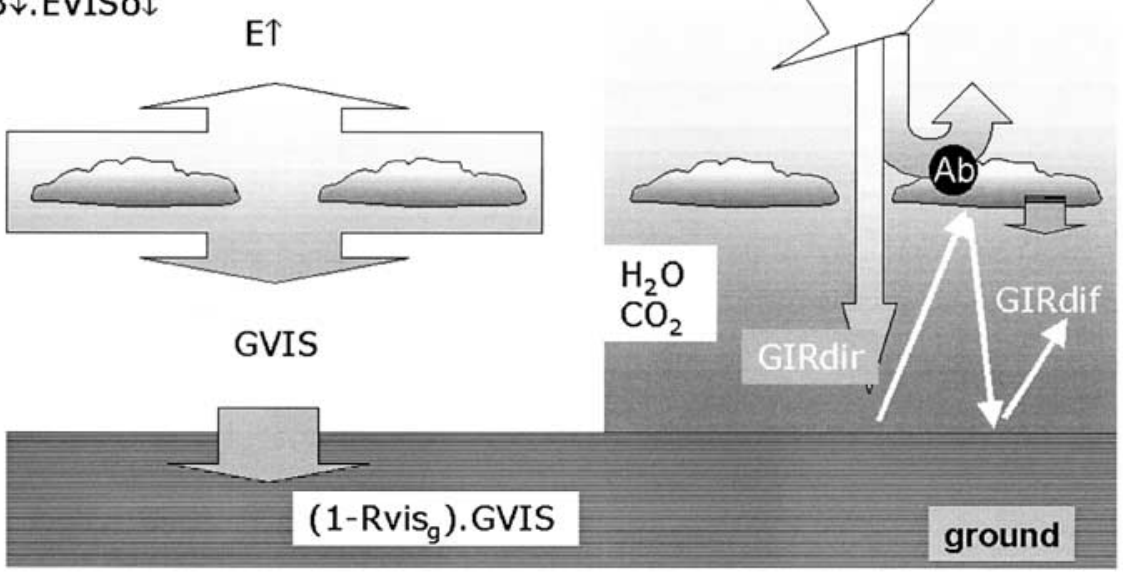

VIS interval (0.4-0.7 $\mu \mathrm{m})$

NIR interval $(0.7-3 \mu \mathrm{m})$

Figure 2. Interaction of solar flux with the atmosphere, as considered in the GL1 model.

It is seen that transmittance is negligible for $\lambda>1.3 \mu \mathrm{m}$, while integrated irradiance is emerging from base level amounts $47.7 \mathrm{~W} \mathrm{~m}^{-2}$ for $Z=0^{\circ}$ and $27.7 \mathrm{~W} \mathrm{~m}^{-2}$ for $Z=45^{\circ}$. The term $\delta G$ will be neglected in equation (4), keeping in mind that errors induced may be bounded by $-15 \mathrm{~W} \mathrm{~m}^{-2}$ for daily mean irradiance in overcast conditions, being lower for a partially cloudy atmosphere.

[14] Figure 2 resumes the set of hypotheses set by the model. From equations (2), (3), and (4), total irradiance $G$ at ground level is assessed by the sum

$$
G=G_{\mathrm{UV} 2}+G_{\mathrm{VIS}}+G_{\mathrm{NIR}} .
$$

[15] Cloudiness may be assessed by a simple expression [Gautier et al., 1980; Stuhlmann et al., 1990]:

$$
C=\left(L-L_{\min }\right) /\left(L_{\max }-L_{\min }\right)=\left(F-F_{\min }\right) /\left(F_{\max }-F_{\min }\right),
$$

which assumes that radiance $L$ measured by the VIS channel is an intermediate value between clear-sky radiance $L_{\text {min }}$ and an overcast (maximum) value $L_{\max }$, respectively, weighted with fractional areas $1-C$ and $C$ within a pixel. It will be shown in section 5 below the convenience of using the locally equivalent expression

$$
C=\left(R-R_{\min }\right) /\left(R_{\max }-R_{\min }\right),
$$

where $R=F / \mu_{o}$ is an estimate of the reflectance for outgoing VIS radiation within a pixel.

[16] In order to allow comparison with ground truth, an "ergodic hypothesis" is assumed, considering that (instantaneous) means of $G$ within targets of $3 \times 3$ pixels are representative of mean hourly values of irradiance observed by a local station pyranometer. The daily mean irradiance $Q$ is obtained by trapezoidal integration of $G$ values of as many as possible images during the day, divided by $86,400 \mathrm{~s}$ (i.e., 24 hours).

\section{Parameterizations}

\subsection{VIS Interval}

[17] Consider first clear-sky conditions. Lacis and Hansen [1974] reported an expression describing reflectance in a plane-parallel dry atmosphere with Rayleigh scattering, absorption by ozone, and a black (nonreflecting) ground:

$$
R_{\mathrm{LH}}=\frac{0.28}{1+6.43 \mu_{o}} .
$$

Although equation (8) is valid for the entire solar spectrum, it is to be noted that reflected irradiance should contain only a slight percentage of NIR radiation because of its low optical depth for Rayleigh scattering. Therefore a first-order global irradiance at TOA and at ground level may be assessed through expressions

$$
\begin{gathered}
E_{\mathrm{VIS}_{p}}=R_{\mathrm{LH} \mu_{o}}, \\
S=R_{\mathrm{VIS}_{p}} \mu_{o} S_{\mathrm{VIS}}, \\
G_{\mathrm{VIS}_{o}}=\mu_{o} S_{\mathrm{VIS}}\left(1-R_{\mathrm{VIS}_{p}}\right),
\end{gathered}
$$

being

$$
R_{\mathrm{VIS}_{o}}=\gamma R_{\mathrm{LH}}, \quad \gamma=S / S_{\mathrm{VIS}}=2.58 .
$$

[18] In the presence of an underlying surface with reflectance $R_{\mathrm{VIS}}$, a multiple reflection process between ground 
and atmosphere is undergone, resulting in a VIS global irradiance assessed by

$$
G_{\mathrm{VIS}}(\text { clear sky })=\mu_{o} S_{\mathrm{VIS}} \frac{1-R_{\mathrm{VIS}_{o}}}{1-R_{\mathrm{VIS}_{g}} R^{*}},
$$

where $R^{*}$ is atmospheric reflectance for diffuse radiation Lacis and Hansen [1974] reported a value $R^{*}=0.065$ (valid for the VIS interval).

[19] Early observations of typical reflectance factors for cloudless conditions over Brazil have shown values $R_{\min } \approx$ 0.06-0.08 (without correction for VIS sensor degradation). A first-order assessment of ground reflectance may be accomplished when values $R<R_{\min }$ are detected by considering only the radiance emerging in the GOES-VIS interval (wavelength $\lambda_{\mathrm{GOES}} \approx 0.65 \mu \mathrm{m}$ ). It can be assumed that radiance detected by the satellite in the VIS interval is mainly composed by (1) a ground-reflected direct beam or (2) atmospheric Rayleigh single scattering of direct beams toward the sensor (zenithal angle $Z_{\mathrm{s}}, \mu_{\mathrm{s}}=\cos Z_{\mathrm{s}}$ ). The optical depth corrected by local pressure and the normalized phase function for Rayleigh scattering are [Paltridge and Platt, 1976; Tanré et al., 1986]

$$
\tau=0.00888 \lambda^{-4.05} P / P_{o}, \quad P(\Theta)=0.603+0.719 \cos ^{2}(\Theta) .
$$

Here, $P$ is atmospheric pressure, $P_{o}=1013 \mathrm{hPa}$, and $\Theta$ is the scattering angle between the incident direct beam and the satellite line-of-sight. Considering that $\tau_{\mathrm{GOES}} \ll 1$, attenuation of a beam is rather low, and Rayleigh scattering by the atmosphere contributes to reflectance factor $F$ by an amount $\delta F \approx+\tau_{\mathrm{GOES}} P(\Theta) / 4 \mu_{\mathrm{s}}$ [Tanré et al., 1986] so that ground reflectance can be assessed by

$$
R_{\mathrm{VIS}_{g}}=R-\tau_{\mathrm{GOES}} P(\Theta) / 4 \mu_{o} \mu_{s} .
$$

Applying equation (13), usual $R_{\mathrm{VIS}}$ values for ground and sea are lower than 0.06-0.08. Equation (11) makes it evident that, except for ground with high-valued reflectance, the correction for multiple reflections will not exceed $0.4 \%$ of $G_{\mathrm{VIS}}$ (clear sky). The resulting errors are certainly lower than those associated with an aerosol presence in the atmosphere.

[20] For cloudy-sky conditions, absorption $A_{\mathrm{VIS}}$ due to ozone may be included in a simple way. Considering that absorption concentrates in the stratosphere, note that (a) radiative transfer within the troposphere is basically conservative; (2) direct solar flux impinging on the top of this lower atmospheric layer is previously attenuated by ozone; and (3) radiance emerging from the troposphere toward the satellite is subsequently attenuated by ozone before attaining the VIS sensor. Therefore emerging irradiance from the troposphere (trop) and global irradiance at the ground are given by the expressions

$$
\begin{aligned}
E_{\mathrm{VIS}_{p}}(\text { trop })+\left(1-R_{\mathrm{VIS}_{g}}\right) G_{\mathrm{VIS}} & =T\left(\mu_{o}\right) \mu_{o} S_{\mathrm{VIS}}, \\
E_{\mathrm{VIS}_{p}}(\text { trop }) & =\frac{F / \mu_{o}}{T\left(\mu_{s}\right)},
\end{aligned}
$$

where $T$ represents ozone transmittance for the solar beam $\left(\mu_{o}=\cos Z_{o}\right)$ and emerging radiance toward the satellite $\left(\mu_{\mathrm{s}}=\right.$ $\cos Z_{\mathrm{s}}$ ) so that the global VIS irradiance can be written as

$$
G_{\mathrm{VIS}}=\mu_{o} S_{\mathrm{VIS}} T\left(\mu_{o}\right)\left(1-R_{\mathrm{VIS}}(\text { trop })\right) /\left(1-R_{\mathrm{VIS}_{g}}\right) .
$$

Here, $x=w_{3} / \mu$ is the ozone optical path and $w_{3}$ is the optical depth. The Total Ozone Mapping Spectrometer program (TOMS) (ftp://toms.gsfc.nasa.gov/pub/eptoms/data) reports vertical optical paths with typical values $w_{3}=0.28 \mathrm{~cm}$ atm (280 Dobson units) over Brazil. Equation (15) assumes a plane-parallel stratified atmosphere. No correction due to spherically layered atmosphere is introduced for high zenith angles since involved irradiation for initial and final images during the diurnal cycle is rather low when compared with daily irradiation.

[21] Transmittances $T\left(\mu_{o}\right)$ and $T\left(\mu_{\mathrm{s}}\right)$ associated with ozone Chappuis bands can be assessed from the Lacis and Hansen [1974] expression for absorptance, adapted for the VIS interval:

$$
T_{\mathrm{VIS}}(x)=1-\gamma \frac{0.02118 x}{1+0.042 x+0.000323 x^{2}} \approx 1-0.02118 \gamma x .
$$

\subsection{UV Interval}

[22] SBDART was applied to the UV interval considering a clean tropical atmosphere and several zenith angles. Spectral net (downward minus upward) irradiance was assessed for heights $z=100,17$, and $0 \mathrm{~km}$. The difference of net fluxes between those levels allows us to assess depletion in each layer. For a sun on the zenith, it is seen that virtually complete depletion in the $0.20-0.28 \mu \mathrm{m}$ interval occurs above $17 \mathrm{~km}$ height. For the interval $0.28-0.35 \mu \mathrm{m}$, net irradiance at TOA is $108 \mathrm{~W} \mathrm{~m}^{-2}$, absorption in the upper layer amounts to $15.5 \mathrm{~W} \mathrm{~m}^{-2}$, and only $1.4 \mathrm{~W} \mathrm{~m}^{-2}$ is depleted below $17 \mathrm{~km}$ level. It is evident that the lower layer would absorb even less energy for an oblique incidence of sunbeam. Therefore GL1.2 assumes the following hypotheses: (1) absorption in the UV2 interval is limited to the stratosphere; thus (2) the radiative balance in the troposphere (equation (3)) reduces to

$$
E_{\mathrm{UV} 2_{p}}(\text { trop })+\left(1-R_{\mathrm{UV} 2_{g}}\right) G_{\mathrm{UV} 2}=T_{\mathrm{UV} 2}\left(\mu_{o}\right) \mu_{o} S_{\mathrm{UV} 2}
$$

(3) ground reflectance in UV2 has the same order of magnitude as in VIS (i.e., $R_{\mathrm{UV} 2_{g}} \approx R_{\mathrm{VIS}_{p}}$ ); (4) planetary reflectance is dominated by clouds, for which reflectance is similar in UV2 and VIS intervals. These conditions allow us to assess $G_{\mathrm{UV} 2}$ as

$$
G_{\mathrm{UV} 2}=\mu_{o} S_{\mathrm{UV} 2}\left(\mu_{o}\right) T_{\mathrm{UV} 2}\left(\mu_{o}\right)\left(1-R_{\mathrm{VIS}}(\operatorname{trop})\right) /\left(1-R_{\mathrm{VIS}_{g}}\right) .
$$

[23] Concerning transmittance in the UV2 interval, UV1 and UV2 fractional contributions to the solar constant amount to $f_{1}=0.012$ and $f_{2}=0.075$, respectively. Therefore if $T_{\mathrm{OZ}}$ is the transmittance of the solar direct beam due to 
UV absorption, while $T_{\mathrm{UV} 1}$ and $T_{\mathrm{UV} 2}$ refer to the UV1 and UV2 intervals, then

$$
\begin{aligned}
& T_{\mathrm{OZ}}=f_{2} T_{\mathrm{UV} 2}\left(\mu_{o}\right)=\left(f_{1}+f_{2}\right) T_{\mathrm{UV}}\left(\mu_{o}\right), \\
& 1-T_{\mathrm{OZ}}\left(\mu_{o}\right)=x\left[1.082(1+138.6 x)^{-0.805}\right. \\
& \left.+0.0658(1+(103.6 x))^{-3}\right],
\end{aligned}
$$

where $x=w_{3} / \mu_{o}$ and $1-T_{\mathrm{Oz}}$ follows a parameterization of Lacis and Hansen [1974].

\subsection{Water Vapor Absorption}

[24] The assessment of $\Delta S\left(\mathrm{H}_{2} \mathrm{O}\right)$ is based on the paper of Howard et al. [1956b] describing laboratory measurements of water vapor absorption. They parameterized their results for $\mathrm{H}_{2} \mathrm{O}$ bands with expressions

$$
A=C+D \log _{10} w+K \log _{10}(P+e), \quad A>A_{c},
$$

where $w$ is the vapor optical path, $e$ is vapor pressure, and $P+e$ is the total pressure (including neutral atmospheric gases). $A$ is an equivalent spectral "slit width" (a variable conceptually similar to absorptance) acting on incident spectral irradiance $S_{\lambda}$ such that absorbed irradiance amounts $\Delta S=A S_{\lambda}$. Incident spectral irradiance is considered constant within the slit width. Each absorption band has its own set of constants $C, D, K ; A_{\mathrm{c}}$ is a critical value below which another function is fitted. Equation (21) may be used for optical paths $w \geq w_{\mathrm{c}}=2 \mathrm{~g} \mathrm{~cm}^{-2}$ for bands between 0.94 and $2.7 \mu \mathrm{m}$ at a constant total pressure. Given that the vapor density is variable with height, a specific humidity "reduced to $1000 \mathrm{hPa}$ " may be assessed in order to provide "equivalent" precipitable water by integration throughout the entire atmospheric column [Liou, 1980]. It is the case of the well-known parameterization of Yamamoto's results (mainly based on the Howard et al. [1956b] report) as presented by Lacis and Hansen [1974]. Zuev [1970] showed that expressions like equation (20) can be used considering the true value $w$ and a total pressure $\langle P+e\rangle$ weighted with the moisture vertical profile. The analysis of several water vapor profiles in Brazil suggests that one should assume an equivalent constant pressure $\langle P+e\rangle \approx 800 \mathrm{hPa}$. This allows one to obtain the following expression:

$$
\Delta S\left(H_{2} O\right)=133+92 \log _{10} w^{*}+2.1 w^{*}, \quad w^{*} \geq 2 \mathrm{~g} \mathrm{~cm}^{-2}
$$

$\Delta S$ is measured in $\mathrm{W} \mathrm{m}^{-2} ; w^{*}=w / \mu$ is the optical path for water vapor and $w$ is the precipitable water in $\mathrm{g} \mathrm{cm}^{-2}$ (or one tenth the value in $\mathrm{kg} \mathrm{m}^{-2}$ ). Equation (21) adds the effects of absorption bands centered at $0.94,1.1,1.38,1.87$, and $2.7 \mu \mathrm{m}$ as well as Fowle's absorption for 0.72 and 0.8 bands [McDonald, 1960]. Fluctuation of $+50 \mathrm{hPa}$ in $\langle P\rangle$ affects results in less than $+1.5 \mathrm{~W} \mathrm{~m}^{-2}$. The results show fairly good agreement with assessments based on Goody's band model [Kratz and Cess, 1985; Ceballos et al., 1992]. Comparison with results of line-by-line codes for tropical and midlatitude summer model atmospheres [Fouquart et al., 1991; Ramaswamy and Freidenreich, 1998; B. Fomin, Kurchatov Institute, personal communication, 2003] shows functional coherence of equation (21) within $\pm 5 \mathrm{~W} \mathrm{~m}^{-2}$ for the interval 2-10 $\mathrm{g} \mathrm{cm}^{-2}$, provided that the constant coefficient value be taken as 142 .

\subsection{Carbon Dioxide Absorption}

[25] In this case, the gas concentration (expressed as a molar fraction or partial volume of dry air) is constant with altitude up to $\sim 80 \mathrm{~km}$, and an equivalent vertical optical path can be calculated by reduction to surface pressure $P_{o}$ using the expression

$$
w_{2}=\int \rho(P)\left[P / P_{o}\right]^{n} d z=\rho_{o} X_{o}
$$

where $n=0.75$ [McClatchey et al., 1971], $\rho_{o}$ is concentration, and $X_{o}$ is the equivalent length of the gas column. McClatchey et al. found $X_{o} \approx 5.5 \mathrm{~km}$ for $P_{o}=1013 \mathrm{hPa}$, testing a variety of standard atmospheres; therefore the equivalent optical depth is $w_{2} \approx 200 \mathrm{~cm}$ atm if $\rho_{o}=360 \mathrm{ppm}$ is considered.

[26] Expressions similar to equation (20) are valid for $\mathrm{CO}_{2}$ absorptance [Howard et al., 1956a] such that the application to constant pressure $P_{o}$ yields

$$
\Delta S\left(\mathrm{CO}_{2}\right)=0.14+12.3 \mu_{o}^{-1 / 2}-8.4 \log _{10} \mu_{o}
$$

with units in $\mathrm{W} \mathrm{m}^{-2}$. It allows one to describe the absorption of $\mathrm{CO}_{2}$ for different solar zenith angles. Equation (23) includes $\mathrm{CO}_{2}$ bands centered at 1.4, 1.6, 2.0 , and $2.7 \mu \mathrm{m}$.

\subsection{Aerosol Effects}

[27] The model assumes the usual aerosol optical depth $\tau_{\mathrm{a}} \ll 1$. In clear-sky conditions we can expect, on average, only one interaction between photons and the atmosphere; therefore monochromatic transmittance for direct radiation is $\exp \left(-\tau_{a} / \mu_{o}\right) \approx 1-\tau_{a} / \mu_{o}$, and the fraction of photons taken off from downward irradiance is

$$
\delta N / N=\delta E_{\lambda} / E_{o_{\lambda}} \approx-\left(\tau_{a} / \mu_{o}\right)[1-\omega+\omega \beta]
$$

where $N$ is the spectral flux of photons at TOA, $E_{O_{\lambda}}$ is the corresponding monochromatic (or spectral) irradiance, $\omega$ is the single-scattering albedo, and $\beta$ is the backscattered fraction. The fraction $\tau_{a} / \mu_{o}$ assesses the probability of the single interaction photon-atmosphere. Considering that aerosol presents a high asymmetry factor $g$ for single scattering, a parameter scaling by the usual $\delta$-Dirac approximations can be applied [Liou, 1992] so that

$$
\begin{gathered}
f \approx g^{2}, \quad g^{\prime}=\frac{g-f}{1-f}, \quad \omega^{\prime}=\omega \frac{1-f}{1-\omega f} \\
\tau^{\prime}=(1-\omega f) \tau, \quad \beta(\mu)=\frac{1}{2}\left(1-\frac{3}{2} g^{\prime} \mu\right),
\end{gathered}
$$

where $f$ is the estimated weight of the $\delta$-Dirac and $\beta$ is assessed by a first-order approximation. Most parts of the Brazilian territory have rural characteristics so that $g \approx 0.65$ [Shettle and Fenn, 1979]. Using Coakley et al. [1983] expressions for the spectral dependence of $\omega$ and $\tau$ on wavelength, it is seen that aerosol optical thickness is restricted to an interval $\lambda(0.3-1.1 \mu \mathrm{m})$ as well as $0.885<$ $\omega<0.939$; thus a typical value $\omega=0.90$ can be assumed. 
Integration of $\delta E_{\lambda}$ (equation (24)) over the $\lambda(0.4-1.1 \mu \mathrm{m})$ interval for different $\mu$ values yields an estimate

$$
\delta E\left[\mathrm{~W} \mathrm{~m}^{-2}\right] \approx-270(1-0.43 \mu) \tau_{0.55}=-435(1-0.43 \mu) \tau_{0.55}^{\prime},
$$

where $\tau_{0.55}$ id the aerosol optical depth at $0.55 \mu \mathrm{m}$ and the last term containing $\tau_{0.55}^{\prime}$ follows from the scaling described by equations (25). It is found that $\delta E \approx-20 \mathrm{~W} \mathrm{~m}^{-2}$ for a background optical depth $\tau_{0.55}=0.1$. A fraction $\omega \beta /(1-$ $\omega+\omega \beta) \approx 0.75$ of $\delta E_{o}$ is associated to reflected flux outside of the atmosphere, representing a contribution of $\sim 0.037$ to planetary reflectance in the VIS channel. These low values introduce a signal which could be used for aerosol detection over oceans [Knapp and Vonder Haar, 2000]. When considering the impact on solar radiation at ground level, equation (21) makes it evident that $\delta E \approx+15-20 \mathrm{~W} \mathrm{~m}^{-2}$ when $w^{*}$ changes from 3.5 to $2.5 \mathrm{~g} \mathrm{~cm}^{-2}$ so that local fluctuations of precipitable water may induce opposite errors of the same order as those associated with the aerosol effect. If seasonal typical values of $w$ are to be used, the lack of an exact definition of atmospheric conditions suggests neglecting low aerosol loadings for a satellite assessment of solar radiation. Additional support to this criterion is given by the overwhelming influence of radiation backscattering by clouds and the fact that the aerosol layer usually lies below the cloud base. Quite different considerations should be made when burning mass aerosol is considered, for example, in considering the Amazonian case during the burning season. For instance, results of Whitlock et al. [1995] show remarkable errors over this region. Further improvements are planned for introducing high aerosol loads in the GL1 model.

\section{Available Satellite and Surface Data}

[28] Daily irradiation $Q$ was available from precision pyranometers in three stations and from Li-Cor pyranometers installed at more than 90 automatic weather stations (meteorological network data provided by CPTEC, see http://www4.cptec.inpe.br). A previous comparison between a Li-Cor and a Kipp \& Zonen pyranometer at CPTEC (Cachoeira Paulista, $22.62^{\circ} \mathrm{S}, 45.00^{\circ} \mathrm{W}$ ) showed fairly good agreement between both instruments for clear-sky as well as for cloudy conditions. Differences for daily mean irradiance are usually not higher than $10 \mathrm{~W} \mathrm{~m}^{-2}$ for irradiances as high as $200-300 \mathrm{~W} \mathrm{~m}^{-2}$ and lower than $4 \mathrm{~W} \mathrm{~m}^{-2}$ for irradiances as low as $50 \mathrm{~W} \mathrm{~m}^{-2}$. Considering a typical daily irradiation of $200 \mathrm{~W} \mathrm{~m} \mathrm{~m}^{-2}$, an accuracy of $5 \%$ will be assumed for data of automatic weather stations (assuming their proper maintenance). Mean daily irradiance $\langle E\rangle$ in $\mathrm{W} \mathrm{m}^{-2}$ will be used in lieu of irradiation $Q$ in $\mathrm{MJ} \mathrm{m}^{-2}$. The first one is of current meteorological use due to its connection with mean evaporation rates, while the second is the usual unit for engineering purposes.

[29] Full-disk images as well as sectors of extended north and south images covering South America and surrounding oceanic regions are recorded at CPTEC. Northern imagery covers $16^{\circ} \mathrm{N}-20^{\circ} \mathrm{S}$ and $87^{\circ}-30^{\circ} \mathrm{W}$. Southern imagerq covers $20^{\circ}-47^{\circ} \mathrm{S}$ and $87^{\circ}-30^{\circ} \mathrm{W}$. Up to two images of each class are obtained within 1 hour. Files have full resolution for channels $2-5$ (providing a brightness temperature with
$4 \times 4 \mathrm{~km}$ resolution at nadir in channels 2 , 4 , and 5 and $4 \times 8$ in channel 3 ). Channel 1 (providing reflectance factor, about $1 \times 1 \mathrm{~km}$ at nadir) is sampled choosing only one pixel from 16 such that a one-to-one correspondence exists with pixels of channel 4. GOES-East currently provides two images within 1 hour. However, transmission of southern images (latitudes higher than $20^{\circ} \mathrm{S}$ ) may present lower rates during some periods of the year when their sequence is substituted by quick-scan monitoring of special weather events over US territory.

[30] A preliminary study concerning cloudiness assessment was performed using a set of multispectral images for the period November-December 1998 (image set 1). These images described a region between latitudes $20^{\circ} \mathrm{S}$ and $30^{\circ} \mathrm{S}$, extending from the Atlantic $\left(41^{\circ} \mathrm{W}\right)$ to $55^{\circ} \mathrm{W}$. The period September-December 2002 (image set 2) was analyzed for solar radiation assessment.

[31] Precipitable water fields were observed in NCEP analyses for 1200 UTC, concluding that typical values are $w=3.5 \mathrm{~g} \mathrm{~cm}^{-2}$ for southern images and $4.5 \mathrm{~g} \mathrm{~cm}^{-2}$ for tropical latitudes within extended north images. A pressure of $950 \mathrm{hPa}$, a constant concentration of $360 \mathrm{ppm}$ for $\mathrm{CO}_{2}$, and an integrated column of $0.28 \mathrm{~cm}$ atm (280 Dobson units) for $\mathrm{O}_{3}$ were adopted, independently of the annual season.

[32] Degradation of the VIS channel signal was corrected by a factor $K$ following an expression used by NOAANESDIS (http://www.oso.noaa.gov/goes), which depends on $n$th day after the GOES 8 launch:

$$
\begin{gathered}
K(n)=1.192(1.0+0.0001688 n), \\
n=2+365(\text { year }-1994)+(\text { julian day }-103) .
\end{gathered}
$$

Factor $K$ reported by the ISCCP team (http://isccp.giss. nasa.gov/docs/calib.html) follows closely expression (27), except for temporary fluctuations. For image set 1 , it can be assumed that $K=1.55$, while values are $\sim 1.82$ for image set 2 .

\section{Results}

[33] Previously, a method for proper cloudiness assessment by equation (6) was analyzed. Image set 1 was used, considering reflectance $R=F / \mu_{o}$ instead of reflectance factor $F$. Numerical values for $F$ used the original calibration for channel 1 [Weinreb et al., 1997], i.e., correction factor $K=1$.

[34] An examination of the minimal values of image set 1 provided the daily cycle of reflectances $R_{\min }$ shown in Figure 3. It is seen that $R_{\min }$ is rather constant during most part of the day. Higher values are observed when the solar irradiance at TOA is lower, justifying the adoption of only one reference value (namely $R_{\min }=0.06$ ). For the oceanic area, $F$ (and not $R$ ) values are rather constant during the day; nevertheless it is seen that $0.02<R<0.06$ from 1000 to 2000 UTC so that assuming $R_{\min }=0.03$ allows for a convenient parameterization. As expected, moderate variations of ground and sea $R_{\min }$ during the daytime (even corrected for VIS sensor degradation) would not substantially affect $G_{\mathrm{VIS}}$ in equations (11) and (15).

[35] Concerning $R_{\max }$, the highest value within the set of images cannot be the proper one since brightest cumulonimbus as well as optically thinner and less reflective 




Figure 3. Daily cycle of minimal reflectance $R_{\min }$ over continent and ocean in November-December 1998 for South America (latitudes between $20^{\circ} \mathrm{S}$ and $30^{\circ} \mathrm{S}$ ). No correction for VIS sensor degradation is used.

stratiform clouds correspond to $C=1$. Equations (6) and (7) have a physical sense only when applied to pixels of the cumuliform cloud field so that the extreme value $R_{\max }$ should be provided by the transition from this field to a stratiform one.

[36] A classification scheme was designed for separating clear-sky-type, cumulus-type, and stratiform-type pixels. At least 10 different data may be used to describe a pixel in multispectral GOES imagery: reflectance $R$ (in channel 1), brightness temperature TB (in channels 2 to 5 ), and texture TX in the five channels. These last are measures of local spatial variability and can be quantified by the variance within a $3 \times 3$-pixel target centered at a given pixel. Factor analysis of these variables applied to a number of images suggests that only three of them are not redundant, namely TB4 and corresponding textures TX1 and TX4. Reflectance $R$ is well but negatively correlated to TB4 (higher and thicker clouds are colder but brighter); nevertheless, $R$ was also included because it better detects lower clouds.

[37] A clustering procedure was applied to image set 1 for discriminating between different types of pixels [Ceballos and Bottino, 2001]. In this procedure, each pixel is identi- fied by a vector ( $R 1, \mathrm{~TB} 4, \mathrm{TX} 1, \mathrm{TX} 4)$. Standardized variables are considered. By visual inspection (nephanalysis) of qualitatively different meteorological situations, 30 sets of pixels were sampled and identified by their four-dimensional centroids ("centers of mass"). A large number of pixels $(\sim 174,000)$ were sampled within a sequence of 10 days, being classified according to the minimal Euclidean distance to centroids ("seeds"). This procedure furnished 30 clusters identified by their four-dimensional centroids, which were adopted as seeds for a new clustering step. The procedure was repeated until an acceptable stabilization of centroids was achieved. The method is similar to "dynamic clustering," described by Sèze and Desbois [1987]. Note that the use of standardized variables avoids correction of $F$ for degradation in channel 1 .

[38] New images were built, labeling pixels with different colors according to their classification. Comparison between nephanalysis and classified scenes allowed us to reduce the whole population to few basic groups, corresponding to cumuliform-type and stratiform-type pixels as well as clearsky-type, cirrus-type, or cumulonimbus-type. Histograms were built describing the cumulated frequency of reflectance for the first two groups.

[39] Table 1 summarizes statistical results at different UTC instants (note that local time over central and eastern Brazil is close to mean solar time). Correction for VIS sensor degradation was applied. Two main facts are observed: (1) reflectance (but not the reflectance factor) is remarkably constant during most part of the diurnal period for each level of cumulated frequency and (2) the upper $5 \%$ of the cumuliform histogram tends to overlap the lower $5-10 \%$ of the stratiform histogram. These results suggest that growing fair-weather cumulus clouds tend to naturally merge into a stratiform cloud at a rather well-defined optical thickness. Overcast conditions $(C=1)$ should be considered beyond the threshold $R_{\max } \approx 0.465$.

[40] It must be remarked that the threshold $R_{\max }$ is a result of the classification method and further identification through image nephanalysis. A reflectance $R \approx 0.5$ corresponds to a cloud with an optical depth of $\sim 15$ (110-160 $\mathrm{m}$ thick) for the stratiform case [Liou, 1992, Table 4.2]. At least in principle the same effect could be obtained for a cloud field described by a cluster of pixels partially but homogeneously filled with $500 \mathrm{~m}$ thick elements (optical depth of $\sim 64$ ), each one exhibiting a reflectance as high as 0.75 . Actually, homogeneous texture for reflectance is the main decision rule for the

Table 1. Reflectance Values for Transition Between Cumuliform-Type and Stratiform-Type Pixels Over S-SE Brazilian Sector for Different Times

\begin{tabular}{|c|c|c|c|c|c|c|}
\hline \multirow[b]{2}{*}{ Cumulated Frequency, \% } & \multicolumn{6}{|c|}{ Time, UTC (LT) } \\
\hline & $1010(0710)$ & $1145(0845)$ & $1445(1145)$ & $1745(1245)$ & $2010(1745)$ & Mean Reflectance \\
\hline \multicolumn{7}{|c|}{ Cumuliform-Type } \\
\hline 50 & 0.20 & 0.14 & 0.17 & 0.17 & 0.19 & 0.17 \\
\hline 90 & 0.48 & 0.43 & 0.43 & 0.42 & 0.43 & 0.43 \\
\hline 95 & 0.53 & 0.49 & 0.49 & 0.48 & 0.51 & 0.49 \\
\hline \multicolumn{7}{|c|}{ Stratiform-Type } \\
\hline 0.45 & 0.45 & 0.45 & 0.49 & 0.46 & 0.41 & 0.45 \\
\hline 10 & 0.50 & 0.48 & 0.48 & 0.50 & 0.45 & 0.50 \\
\hline 50 & 0.67 & 0.65 & 0.65 & 0.65 & 0.60 & 0.64 \\
\hline
\end{tabular}



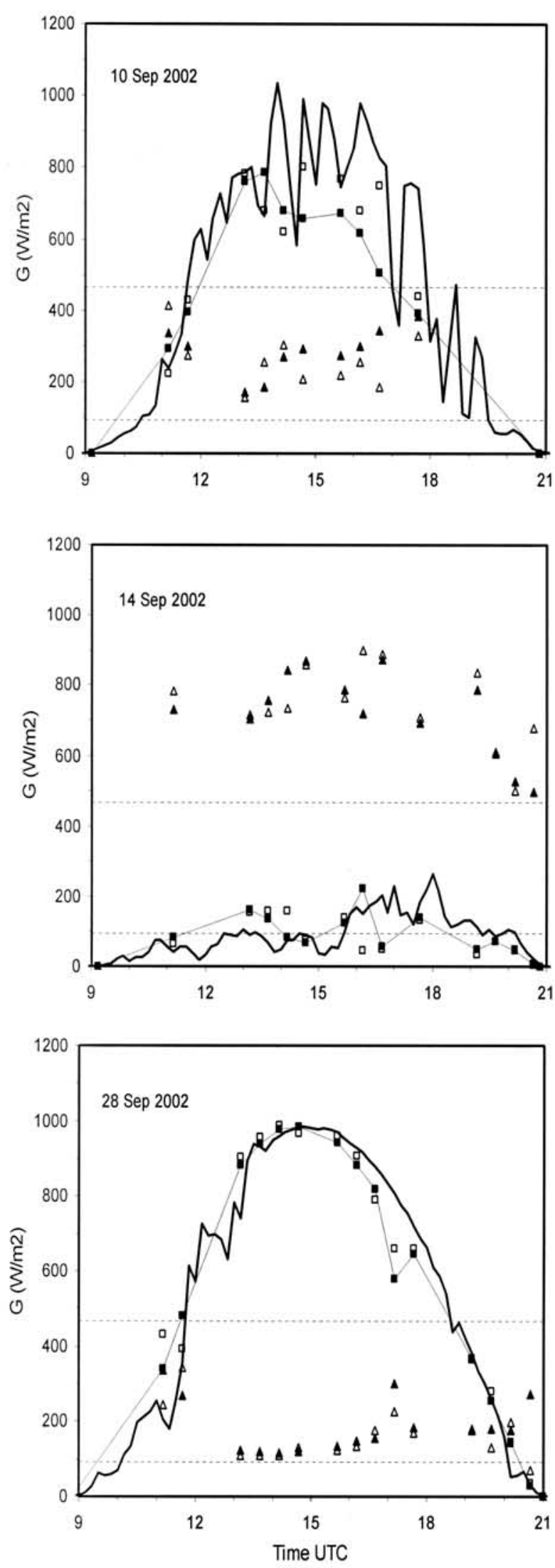

cloud classification method; it is expected that an observer beneath the cloud field would classify the local situation as overcast. It is to be noted that the $R_{\max }$ value may be seasonal as well as characteristic of the region considered, thus depending implicitly on a second threshold in TB.

[41] Hereafter, thresholds $R_{\min }=0.093$ and $R_{\max }=0.465$ will be adopted for the Brazilian territory. The Lacis and Hansen model (equation (11)) will be assumed below $R_{\min }$, while overcast conditions $(C=1)$ will be considered over the threshold $R_{\max }$. Note that this scheme may induce the GL1.2 model to interpret thinner cirrus clouds as a partially cloudy scene.

[42] Figure 4 illustrates daily cycles assessed by the GL1.2 model for three days in September 2002 at the CPTEC site as well as measurements by a precision pyranometer. Estimated reflectances $R_{\mathrm{VIS}}$ are included as well as threshold levels $R_{\min }$ and $R_{\max }$ (reflectance is multiplied by a factor of 1000). It can be seen that (1) moderate variations of low cloudiness are well followed by $1 \times 1$ as well as by $3 \times 3$ targets; (2) inhomogeneous cloud fields (with highly variable irradiance) might eventually be better described by $1 \times 1$ targets (in this case a good navigation is a critical factor for comparisons with ground truth); and (3) estimates during overcast days are satisfactory, although positive or negative errors cannot be avoided.

[43] Underestimation was observed after local noon in November, inducing higher deviations for the daily mean. This effect is clearly due to increased convection from equinox to summer in a hilly environment (as is the case for the CPTEC site), when highly developed clouds are present during the afternoon, reflect solar radiation, and induce an additional source of radiation. This effect is hardly described by a simple model. Nevertheless, it can be said that daily cycles are reasonably fitted in all cases, considering that the GL1.2 model is generated by a set of simplifying hypotheses.

[44] Figure 5 illustrates the quality of assessment for daily mean irradiance $\langle E\rangle$ (irradiation $Q$ in $\mathrm{J} \mathrm{m}^{-2}$ divided by 86,400 s) during the September-October period at the CPTEC site. Only days with more than six images were chosen. Some days presented anomalous behavior of the daily cycle, seemingly due to unexpected navigation errors, and were excluded. A number of 51-61 possible days is presented. A fairly good linearity of $\langle E\rangle$ assessed by GL1.2 related to ground truth $\langle P Y R\rangle$ is found. The same figure includes VIS + UV mean irradiance $\left\langle E_{\mathrm{VISUV}}\right\rangle$. Note that $\left\langle E_{\mathrm{VISUV}}\right\rangle$ and $\langle E\rangle$ are identical for $\langle E\rangle<80 \mathrm{~W} \mathrm{~m}^{-2}$ due to hypotheses concerning overcast conditions; for higher values a linear or a logarithmic behavior of $\left\langle E_{\mathrm{VISUV}}\right\rangle$ related to pyranometric measurements may be suggested. A minimal squares fit yields the following expressions $\left(r^{2}\right.$ being the determination coefficient):

Figure 4. Daily cycles of solar irradiance at Cachoeira Paulista (CPTEC site) in September 2002 (days 28, 10, and 14). The solid line represents pyranometer data. Squares represent model GL1.2. Triangles are VIS reflectance $(\times 1000)$. Empty symbols represent only one pixel. Filled symbols represent $3 \times 3$ arrays. Horizontal lines correspond to $R_{\min }$ and $R_{\max }$ 




Figure 5. Daily mean irradiances at Cachoeira Paulista (CPTEC site), September-October 2002: comparison of GL1.2 model (empty squares) with ground truth. Black squares represent component UV + VIS for the GL model. Crosses are measurements by a Li-Cor pyranometer.

$$
\begin{array}{ll}
\langle E\rangle=1.028 \text { PYR }-13, & r^{2}=0.9766, \text { or } \\
\langle E\rangle=0.98 \text { PYR }, & r^{2}=0.9741 ; \\
\left\langle E_{\mathrm{VISUV}}\right\rangle=83.7 \mathrm{LN}(P Y R / 24.8), & r^{2}=0.9365, \text { or } \\
\left\langle E_{\mathrm{VISUV}}\right\rangle=0.558 \text { PYR }+20, & r^{2}=0.967 .
\end{array}
$$

These expressions make evident a good performance of the GL1.2 model. For higher $\langle E\rangle$, variable deviations from ground truth make evident the effects of uncertainties in pixel navigation and fluctuations of precipitable water and aerosol load. The observed mean error for $\langle E\rangle$ lies between values of -6 and $-4 \mathrm{~W} \mathrm{~m}^{-2}$, depending on considering more than 6 or more than 12 images in a day. In all cases, the standard deviation is $\sim 15 \mathrm{~W} \mathrm{~m}^{-2}$; therefore the expected standard deviation for the monthly mean should be $15 / \sqrt{30} \approx 3 \mathrm{~W} \mathrm{~m}^{-2}$ for a single site. Percent errors related to a typical mean irradiance $\left(185 \mathrm{~W} \mathrm{~m}^{-2}\right)$ are about $-2.7 \%$ (systematic) $\pm 10 \%$ (random) on a daily basis.

[45] Figure 5 also shows the daily irradiance as measured by a Li-Cor instrument close to a Kipp \& Zonen pyranometer. As mentioned in section 4, it exhibits excellent behavior, with a mean error of $-5 \mathrm{~W} \mathrm{~m}^{-2}$ and a standard deviation of $5 \mathrm{~W} \mathrm{~m}^{-2}\left(\sim 2.5 \%\right.$ of $200 \mathrm{~W} \mathrm{~m}^{-2}$ in each case). The mean error of the GL1.2 model amounts to $-2 \mathrm{~W} \mathrm{~m}^{-2}$ when considering Li-Cor as a reference. These facts give support for performing comparisons of the GL1.2 model with data of automatic stations of the Brazilian network processed at CPTEC (assuming 5\% accuracy, even if properly installed and maintained).

[46] Figure 6 allows a comparison with precision pyranometers installed at Florianópolis (university campus, city in a coastal environment), São Paulo (university campus, urban industrial environment), and Cachoeira Paulista (rural region). October 2002 data were used. See the geographical location in Figure 8. It is evident that there is a generally good matching with ground truth, although two cases of deviation must be noted. The first one refers to higher irradiances for São Paulo: GL1.2 represents satisfactorily cloudy day irradiation but systematically overestimates irradiation for clear-sky days. As a matter of fact, São Paulo city is characterized by a persistent high aerosol load, which is temporarily washed out during rainy situations. Florianópolis exhibits a cleaner atmosphere, and higher irradiation tends to be properly matched by GL1.2. The second case to be noted is the underestimation of GL1.2 in partially cloudy situations. As seen in Figure 4, variable cloudiness during 1 hour is hardly described by a $3 \times 3$ pixel array and sometimes is better assessed using only one pixel. However, precise matching between this one and the ground site location is difficult to get since images in the VIS channel were sampled (one VIS pixel in an environment of $\sim 4 \times 4 \mathrm{~km}$ ).

[47] Figure 7 illustrates the behavior of the GL1.2 model when compared with monthly mean values of automatic stations in $\sim 80$ different sites throughout the Brazilian territory (see Figure 8). Four months are included (September-December 2002). Considering that the data refer to specific locations and not to the average over a large area, the model exhibits good linearity. Nevertheless, it is seen that mean errors are different for each month. Local differences between model and ground truth may be attributed to a variety of factors. At least (1) automatic stations may exhibit local bias; (2) VIS pixel sampling and the inaccurate navigation of the site location may introduce biases because of local characteristics of cloudiness (especially in a coastal region or in a valley), included anisotropy; and (3) largescale parameters may (and do) have local deviations. Also, the following facts should be considered.



Figure 6. Daily mean irradiance for October 2002 for the Florianópolis, São Paulo, and Cachoeira Paulista sites. Ground data were provided by precision pyranometers. 
[48] 1. Precipitable water is neither constant in time nor over too large areas (for instance, values lower than $4.5 \mathrm{~g} \mathrm{~cm}^{-2}$ were observed for Brazil's northeastern region, while values as high as $5.5 \mathrm{~g} \mathrm{~cm}^{-2}$ may be observed over the Amazonian region). As already stated, a difference of $\pm 1 \mathrm{~g} \mathrm{~cm}^{-2}$ may induce opposite errors of about $+5-6 \mathrm{~W}$ $\mathrm{m}^{-2}$ on days with high values of mean irradiance (and low cloudiness).

[49] 2. The influence of the local ground albedo may be not negligible. Reflectance in the VIS interval may drop from 0.09 to 0.06 for vegetation in semiarid regions after rainy days. From equation (15), it is easily seen that a change of about $+3 \%$ (or $+6 \mathrm{~W} \mathrm{~m}^{-2}$ if $\langle E\rangle \approx 160 \mathrm{~W} \mathrm{~m}^{-2}$ ) would be induced in $G_{\mathrm{VIS}}$.

[50] 3. The local production of burning mass may introduce high absorption, mainly in the VIS spectrum. Figure 7 allows us to note at least three sites with a "ground truth" of $\sim 200-300 \mathrm{~W} \mathrm{~m}^{-2}$, showing excessively large values of the GL1.2 model in September (overestimation of $\sim 40-50 \mathrm{~W}$ $\mathrm{m}^{-2}$ ). They are located in the Amazon region, where September is just a very active burning mass period.

[51] 4. Perhaps the main source of errors is cloud cover assessment. Parameter $R_{\min }$ is associated to (variable) local albedo, and $R_{\max }$ can be associated to local dynamics of cloud generation, which, in turn, may exhibit an annual cycle.

[52] 5. Errors in correction for VIS sensor degradation have second-order influence if compared with the consequences of assuming isotropic reflectance by clouds. Convective well-developed clouds certainly introduce not negligible deviations from the lambertian hypothesis.

[53] Despite these limitations, the whole set of points in Figure 7 shows a general mean error $m=-5 \mathrm{~W} \mathrm{~m}^{-2}$ and a standard deviation $s=15 \mathrm{~W} \mathrm{~m}^{-2}$ (similar to results found for Figure 5). Preceding numbers are coherent with the accuracy proposed by Whitlock et al. [1995] but refer to individual sites. When data are intended to be used for

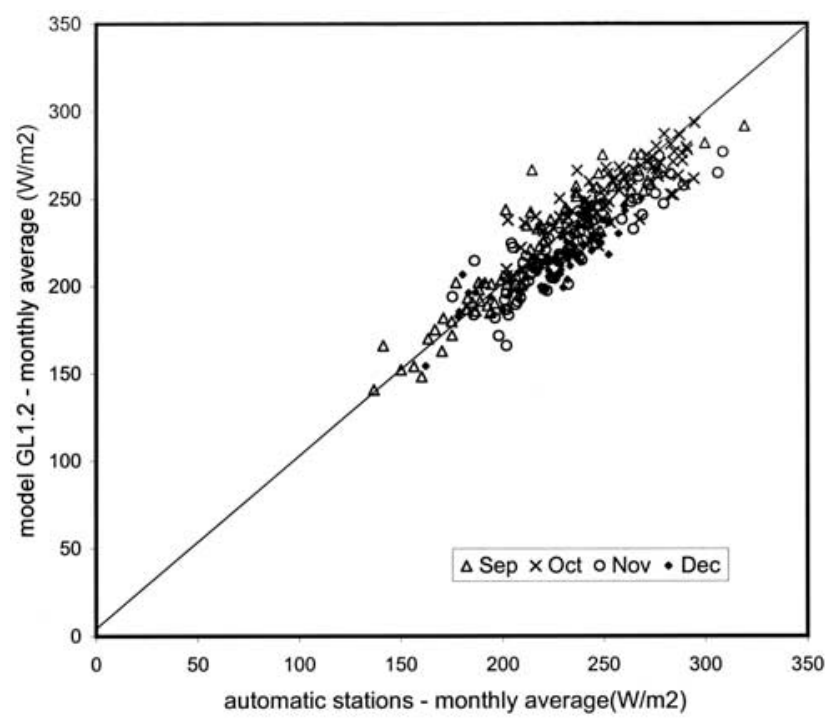

Figure 7. Comparison of GL1.2 daily irradiance (averaged over 1 month) with measurements of about 80 automatic weather stations. The geographic distribution is shown in Figure 8.

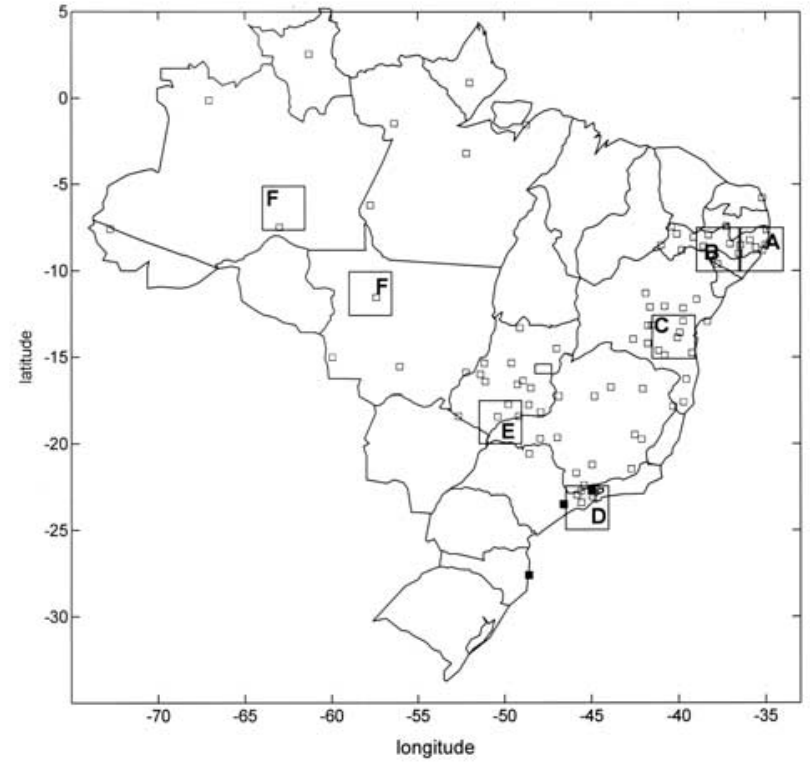

Figure 8. Geographical distribution of stations considered for point comparison in this work. Automatic weather stations (Li-Cor pyranometers) are indicated with open squares. The locations of sites at Florianópolis, São Paulo, and Cachoeira Paulista are labeled with solid squares. Letters A to F label $2.5^{\circ} \times 2.5^{\circ}$ cells for the comparison of mean values over larger areas.

global or regional climatological purposes, model output is usually reduced to grid points representing means within cells with hundreds of kilometers size [Whitlock et al., 1995; Pinker et al., 2001; Stackhouse et al., 2001]. A test was performed for six cells of $2.5^{\circ} \times 2.5^{\circ}$, located as shown in Figure 8 (labels A to F). Cells A-E contain at least three automatic stations, and their average values are expected to be representative of model means within the cell. Cell A is located in the transition from coast to inland in northeastern Brazil, while $\mathrm{B}$ and $\mathrm{C}$ are in a semiarid region. Cell $\mathrm{D}$ is in Paraiba Valley (São Paulo State) with low-height hills; E is located in a plane inland region between Goias and Minas Gerais States. In the Amazon region (cells F), at most one station is located in any cell; a couple of them were taken, assuming regional homogeneity of solar radiation statistics. The cells are spread over a large area of several million square kilometers.

[54] Table 2 presents resulting values as well as the standard deviation of the daily difference between the model and the average of automatic stations ( $\sim 30$ values in each month). The common behaviors along 4 months are (1) a standard deviation (cells A-E) of $\sim 15-20 \mathrm{~W} \mathrm{~m}^{-2}$ and (2) similarly to the general mean over the network, there is a negative trend of the mean error (cells A-F) from September to December. Absolute mean errors $|m|>10$ and $|s|>25$ are labeled in boldface. The Amazon cell is poorly represented by two sites, but the results make evident the strong effect of the forest fire season: Aerosol released by burning mass is progressively absent during the 4 months of transition from dry to wet season (when burning stops). High mean errors make evident the need to improve the GL1 model by inclusion of aerosol effect in this region. 
Table 2. Comparison of Model GL1.2 With Station Values: Averages Within Cells of $2.5^{\circ} \times 2.5^{\text {oa }}$

Cell Stations September October November December \% of $\langle G\rangle$

\begin{tabular}{lccccc} 
& \multicolumn{4}{c}{$\langle G\rangle$} \\
$\mathrm{A}$ & 6 & 247 & 237 & 255 & 243 \\
$\mathrm{~B}$ & 5 & 264 & 273 & 283 & 250 \\
$\mathrm{C}$ & 7 & 188 & 244 & 232 & 225 \\
$\mathrm{D}$ & 10 & 183 & 238 & 214 & 231 \\
$\mathrm{E}$ & 3 & 235 & 271 & 218 & 222 \\
$\mathrm{~F}$ & 2 & 208 & 214 & 214 & 193
\end{tabular}

\begin{tabular}{lcccccc}
\multicolumn{7}{c}{$m$} \\
A & 6 & $\mathbf{1 7}$ & $\mathbf{1 0}$ & -7 & 5 & +7 to -3 \\
B & 5 & 4 & -4 & $-\mathbf{1 6}$ & $-\mathbf{1 4}$ & +2 to -6 \\
C & 7 & -3 & -7 & $-\mathbf{1 9}$ & $-\mathbf{1 6}$ & -2 to -8 \\
D & 10 & 2 & 10 & -5 & $-\mathbf{2 0}$ & +1 to -9 \\
E & 3 & 4 & -1 & $-\mathbf{1 3}$ & $-\mathbf{1 3}$ & +2 to -6 \\
F & 2 & $\mathbf{4 2}$ & $\mathbf{3 1}$ & $\mathbf{1 4}$ & $-\mathbf{1 1}$ & +20 to -6 \\
Network & 78 & 4 & -2 & -11 & -10 & +2 to -5
\end{tabular}

\begin{tabular}{lcccccc}
\multicolumn{5}{c}{$s$} & & \\
A & 6 & 13 & 13 & 15 & 14 & $5-6$ \\
B & 5 & 14 & 10 & 13 & 16 & $4-6$ \\
C & 7 & 15 & 18 & 17 & 17 & $7-8$ \\
D & 10 & 17 & 22 & 18 & 23 & $9-10$ \\
E & 3 & 16 & 13 & 19 & 18 & $7-9$ \\
F & 2 & 23 & $\mathbf{3 1}$ & 20 & $\mathbf{2 5}$ & $11-14$ \\
Network & 78 & 17 & 17 & 14 & 11 & $5-8$ \\
\hline
\end{tabular}

${ }^{\mathrm{a}}$ For each cell is shown the number of stations, their average $\langle G\rangle$, model mean error $m$, and standard deviation $s$ of daily errors. The last row shows $m$ and $s$, considering monthly values of GL1.2 compared with individual stations of the network. Units are in $\mathrm{W} \mathrm{m}^{-2}$. Absolute mean errors $|m|>10$ and $|s|>25$ are labeled in boldface.

Cells $\mathrm{A}$ and $\mathrm{B}$ describe the transition from coastal to semiarid inland region and make evident the importance of better defining local parameters $R_{\min }$ and $R_{\max }$ as well as the ground albedo. This last may substantially differ from the humid coastal cell A (also including the oceanic surface) to the semiarid one B, which, in turn, should vary from the dry to the wet season.
[55] Note that cloud parameters have been defined for a region representative of cells $\mathrm{D}$ and $\mathrm{E}$. For cells $\mathrm{B}-\mathrm{D}$, a fairly low mean error is evident in September and October. As a matter of fact, the mean error and the negative trend are similar for these cells and follow the transition to the summer season, when convective cloud formation becomes usual. An annual cycle of cloud parameters should be expected. These results suggest the need to build grid files containing monthly or at least quarterly information about proper values of $R_{\min }, R_{\max }$, and the mean ground albedo. A remaining difficulty in managing spatially and radiative inhomogeneous effects of convective clouds can be expected; an analysis of this additional limitation requires further careful analysis.

[56] In order to bound the impact on model results induced by the fluctuation of main parameters, 10 days in September 2002 were considered. Table 3 contains statistics of model deviation within cells $\mathrm{A}-\mathrm{F}$, assuming an average of included stations as "ground truth." The first three columns show a comparison with the original model. Different values of precipitable water $w\left(2.5-4.5 \mathrm{~g} \mathrm{~cm}^{-2}\right)$ and the reflectance threshold $R_{\max }(0.56-0.76)$ were considered. Only days with a high number of available images were taken.

[57] It is seen that cells $\mathrm{A}$ and $\mathrm{F}$ exhibit larger mean differences for the original model (like in Table 2). Cell $\mathrm{F}$ (Amazon region) presented burning events in those days and mean deviation amounts of about $+50 \mathrm{~W} \mathrm{~m}^{-2}$. Cells B$\mathrm{E}$ exhibit low values of the mean deviation and standard error. Fluctuations in precipitable water would be rather negative (except for cell F); it is seen that fluctuations of $-1 \mathrm{~g} \mathrm{~cm}^{-2}$ in $w$ induce positive deviations of about $+2-$ $4 \mathrm{~W} \mathrm{~m}^{-2}$. The effect of increased $R_{\max }$ is to reduce assessed cloudiness (and therefore to increase irradiance). Table 3 shows that the impact on the model deviation should be about $+5 \mathrm{~W} \mathrm{~m}^{-2}$ for $\delta R_{\max }=+0.1$ (or about $+15 \mathrm{~W} \mathrm{~m}^{-2}$ if

Table 3. Deviation of GL1.2 Model Related to "Ground Truth": Impact of Variability of $w$ and $R_{\max }$ Parameters

\begin{tabular}{|c|c|c|c|c|c|c|c|c|c|}
\hline & Sites & Model & Deviation & $w=2.5$ & $w=3.5$ & $w=4.5$ & $R_{x}=0.56$ & $R_{x}=0.66$ & $R_{x}=0.76$ \\
\hline \multicolumn{10}{|c|}{ Cell $A$} \\
\hline Mean & 220 & 251 & 26 & 40 & 36 & 34 & 37 & 33 & 31 \\
\hline SD & 34 & 24 & 15 & 15 & 15 & 15 & 15 & 15 & 15 \\
\hline \multicolumn{10}{|c|}{ Cell B } \\
\hline Mean & 233 & 242 & 9 & -5 & -8 & 15 & 22 & 28 & 32 \\
\hline SD & 38 & 43 & 16 & 35 & 35 & 16 & 18 & 19 & 20 \\
\hline \multicolumn{10}{|c|}{ Cell C } \\
\hline Mean & 181 & 179 & -2 & -3 & -5 & -6 & 5 & 15 & 24 \\
\hline SD & 48 & 53 & 9 & 9 & 9 & 8 & 7 & 6 & 7 \\
\hline \multicolumn{10}{|c|}{ Cell D } \\
\hline Mean & 208 & 211 & 3 & 19 & 16 & 14 & 21 & 26 & 30 \\
\hline SD & 51 & 56 & 23 & 14 & 14 & 13 & 14 & 13 & 12 \\
\hline \multicolumn{10}{|c|}{ Cell $E$} \\
\hline Mean & 233 & 236 & 5 & 13 & 10 & 5 & 11 & 17 & 22 \\
\hline SD & 39 & 43 & 8 & 23 & 12 & 10 & 10 & 9 & 9 \\
\hline \multicolumn{10}{|c|}{ Cell F } \\
\hline Mean & 202 & 252 & 49 & 59 & 51 & 49 & 73 & 78 & 82 \\
\hline SD & 35 & 54 & 29 & 50 & 29 & 28 & 38 & 37 & 36 \\
\hline
\end{tabular}

${ }^{\text {a }}$ Statistics of cells A-F over 10 days in September 2002, showing deviation of model related to the daily mean value of stations inside each cell (mean and standard deviation (SD)). 
$R_{\max }=0.76$ were adopted as threshold). It is interesting to note that the temporal standard deviation of model errors is usually conserved in despite of changes in the main parameters. These numbers suggest that (1) usual fluctuations in precipitable water would tend to increase the model deviation (which is itself positive) and that (2) increasing the threshold $R_{\max }$ would induce an even higher effect. Last but not least, consider the following.

[58] 1. A better parameterization of water vapor absorption for the direct beam (equation (21)) should actually contribute to a better assessment of NIR irradiance; the abovementioned correction of $+9 \mathrm{~W} \mathrm{~m}^{-2}$ suggests an improvement of about $-4 \mathrm{~W} \mathrm{~m}^{-2}$ for more or less clearsky days.

[59] 2. In this context, a frequent update of precipitable water at a regional scale should contribute to model accuracy; nevertheless, the monthly output of circulation models could not allow the management of the effect (on a daily scale) of high variations due to the passage of frontal systems.

[60] 3. The $R_{\max }$ threshold seems to be appropriate, although regional estimates might improve its use; it may be thought that the observed trend in model deviations could be induced by seasonal variations of cloud field genesis.

[61] 4. The modeling of the aerosol influence remains an important question but seems to be mainly concentrated in the Amazon region during the burning season. In this case, an additional problem will be the proper evaluation of the optical depth (which is by no means described by climatological means in a day-by-day sequence).

\section{Summary and Conclusions}

[62] Despite the complex characteristics of solar radiation transfer in the atmosphere, the results strongly suggest that the estimation of daily mean irradiation using a simple but physically consistent model may attain the requirement of bias within $\pm 10 \mathrm{~W} \mathrm{~m}^{-2}$ and a standard deviation lower than $25 \mathrm{~W} \mathrm{~m}^{-2}$. Only VIS channel information of GOES 8 is used by the model. On one hand, observed reflectance allows us to estimate global irradiance over the VIS interval; on the other hand, cloud cover $C$ is assessed by a usual algorithm. In order to assess the $C$ variable, a minimal reflectance $R_{\min }=0.09$ for clear-sky conditions and a threshold $R_{\max }=0.465$ were found, above which overcast conditions are assumed.

[63] The GL1.2 version disregards aerosol content and therefore assumes a nonabsorbing troposphere in the VIS interval $(0.4-0.7 \mu \mathrm{m})$. The included UV interval and ozone influence are parameterized by simple expressions. Also, clouds are assumed opaque in NIR $(0.7-3 \mu \mathrm{m})$, while the atmosphere has no scattering in this interval. It considers a limited set of constant physical parameters: precipitable water, ozone, and carbon dioxide total content, ground reflectance in VIS and NIR, cloud-base reflectance, and $R_{\text {min }}$ and $R_{\text {max }}$, assuming that they are constant throughout extended regions over Brazil. These simplifying assumptions lead to a model which exhibits fairly good agreement with observed daily mean irradiances of three different sites in southeastern Brazil.

[64] A comparison was performed with a set of $\sim 80$ automatic stations distributed over a large Brazilian area in
September-December 2002. For monthly means, the GL1.2 version exhibits errors with a mean deviation generally within $\pm 10 \mathrm{~W} \mathrm{~m}^{-2}$ and a standard deviation lower than $20 \mathrm{~W} \mathrm{~m}^{-2}$. These numbers seem consistent, even when considering that radiometers adopted for "ground truth" have a limited precision of $\sim 5 \%$. Similar numbers are obtained for the average over different $2.5^{\circ} \times 2.5^{\circ}$ cells. These results are close to the requirements suggested by Whitlock et al. [1995].

[65] The introduction of absorption by aerosol is not only convenient for improving the model but becomes necessary for avoiding large errors in areas influenced by forest and agricultural fires, in particular the Amazon region during burning season. Nevertheless, present results make evident the fact that partition in two broadband intervals can yield rather accurate results, with the advantage of accepting a simple tuning of constants or parameterizations of physical phenomena.

[66] A general trend for model deviation is observed from September to December. An annual cycle of mean deviation with amplitude of $\sim 10 \mathrm{~W} \mathrm{~m}^{-2}$ is suggested. Similar results are obtained for averages over $2.5^{\circ} \times 2.5^{\circ}$ cells, suggesting a main association with changes in basic parameters $R_{\text {min }}$ and $R_{\max }$ used for cloud cover assessment. A annual cycle for these parameters may be expected as well as their variation from region to region.

[67] It is recommended to build lookup tables, gridding the monthly and geographical distributions for $R_{\min }, R_{\max }$. Similar tables describing the ground reflectance distribution and precipitable water (arising from circulation model outputs or from satellite retrieval) would also contribute to improving model results. The introduction of aerosol effects will require the same type of lookup table if data are introduced as a climatology or as a monitoring product of another satellite. It is expected that the improvement of physical parameters and the eventual compensation of different error sources will induce the accuracy proposed by Whitlock et al. [1995], in particular for mean deviation. This is a matter of further study.

[68] Acknowledgments. The authors are thankful to LABSOLARUniversidade Federal de Santa Catarina for pyranometric data of Florianópolis (provided by an instrument included in BSRN-Baseline Solar Radiation Network) and to Amaury de Oliveira (Astronomical and Geophysical Institute, University of São Paulo) for daily irradiation data of São Paulo. They also thank the kind disposition of line-by-line calculations performed by Boris Fomin (Kurchatov Institute, Moscow, presently visiting CPTEC). This work was partially granted by CNPq-Brazilian National Council for Science and Technology Development through a fellowship of the first author.

\section{References}

Cano, D., J. M. Monget, M. Albuisson, H. Guillard, N. Regas, and L. Wald (1986), A method for the determination of the global solar radiation from meteorological satellite data, Sol. Energy, 37, 31-39.

Ceballos, J. C., and M. J. Bottino (2001), Improved solar radiation assessment by satellite using cloud classification, in IRS 2000: Current Problems in Atmospheric Radiation, pp. 60-63, A. Deepak, Hampton, Va.

Ceballos, J. C., and G. B. A. Moura (1997), Solar radiation assessment using Meteosat 4-VIS imagery, Sol. Energy, 60, 208-219.

Ceballos, J. C., G. B. A. Moura, V. F. Bezerra, and J. d'A. A. Farias (1992), Desempenho de heliógrafos e actinógrafos na estimativa de insolação e fluxo direcional, Rev. Bras. Meteorol., 7, 563-581.

Ceballos, J. C., R. C. G. Pereira, E. J. B. Bastos, and E. C. Moraes (1998), Solar radiation monitoring using a physical model and GOES 8 VIS imagery, paper presented at the 9th Conference on Satellite Meteorology and Oceanography, Fr. Meteorol. Soc., Paris, May. 
Coakley, J. A., R. D. Cess, and F. B. Yurevich (1983), The effect of tropospheric aerosols on the Earth's radiation budget: A parameterization for climate models, J. Atmos. Sci., 40, 116-138.

Fouquart, Y., B. Bonnel, and V. Ramaswamy (1991), Intercomparing shortwave radiation codes for climate studies, J. Geophys. Res., 96, $8955-$ 8968

Gautier, C., G. Diak, and S. Masse (1980), A simple physical model to estimate incident solar radiation at the surface from GOES satellite data, J. Appl. Meteorol., 19, 1005-1012.

Howard, J. N., D. E. Burch, and D. Williams (1956a), Infrared transmission in synthetic atmospheres. II: Absorption by carbon dioxide, J. Opt. Soc. Am., 46, 237-241.

Howard, J. N., D. E. Burch, and D. Williams (1956b), Infrared transmission in synthetic atmospheres. III: Absorption by absorption by water vapor, J. Opt. Soc. Am., 46, 242-245.

Iqbal, M. (1983), Introduction to Solar Radiation, 390 pp., Academic, San Diego, Calif.

Knapp, K. R., and T. H. Vonder Haar (2000), Calibration of the Eighth Geostationary Observational Environmental Satellite (GOES-8) imager visible sensor, J. Atmos. Oceanic Technol., 17, 1639-1644.

Kratz, D. P., and R. D. Cess (1985), Solar absorption by atmospheric water vapor: A comparison of radiation models, Tellus, Ser. B, 37, 53-63.

Lacis, A. A., and J. E. Hansen (1974), A parameterization for the absorption of solar radiation in the Earth's atmosphere, J. Atmos. Sci., 31, 118-133.

Liou, K. N. (1980), An Introduction to Atmospheric Radiation, 391 pp., Academic, San Diego, Calif.

Liou, K. N. (1992), Radiation and Cloud Processes in the Atmosphere. Theory, Observation and Modeling, 487 pp., Oxford Univ. Press, New York.

Lubin, D., and P. Weber (1995), The use of cloud reflectance functions with satellite data for surface radiation budget estimation, J. Appl. Meteorol., 34, 1333-1347.

McClatchey, R. A., R. W. Fenn, J. E. A. Selby, E. E. Volz, and J. S. Garing (1971), Optical properties of the atmosphere (revised), Environ. Res. Pap. 354, Air Force Cambridge Res. Lab., Bedford, Mass.

McDonald, J. E. (1960), Direct absorption of solar radiation by atmospheric vapor, J. Meteorol., 17, 319-328.

Nunes, M. (1993), The development of a satellite-based insolation model for the tropical western Pacific ocean, Int. J. Climatol., 13, 607-627.

Paltridge, G. W., and C. M. R. Platt (1976), Radiative Processes in Meteorology and Climatology, 399 pp., Elsevier Sci., New York.

Pereira, E. B., S. L. Abreu, E. Stuhlmann, M. Rieland, and S. Colle (1996) Survey of the incident solar radiation in Brazil by use of Meteosat satellite data, Sol. Energy, 57, 125-132.

Pinker, R. T., and J. A. Ewing (1985), Modeling surface solar radiation: Model formulation and validation, J. Clim. Appl. Meteorol., 24, 389401

Pinker, R. T., and I. Laszlo (1992), Modeling surface solar irradiance for satellite applications on global scale, J. Appl. Meteorol., 31, 194-211.

Pinker, R. T., R. Frouin, and Z. Li (1995), A review of satellite methods to derive surface shortwave irradiance, Remote Sens. Environ., 51, 108124

Pinker, R. T., I. Laszlo, and B. Zhang (2001), Pathfinder large scale radiative fluxes: Data availability and their use in climate research, in IRS 2000: Current Problems in Atmospheric Radiation, pp. 481-484, A. Deepak, Hampton, Va.

Pope, S. K., F. P. J. Valero, W. D. Collins, and P. Minnis (2002), Comparison of ScaRaB, GOES 8, aircraft, and surface observations of the absorption of solar radiation by clouds, J. Geophys. Res., 107(D11) doi:10.1029/2001JD001139.
Ramaswamy, V., and S. M. Freidenreich (1998), A high-spectral resolution study of the near-infrared solar flux disposition in clear and overcast atmospheres, J. Geophys. Res., 103, 23,255-23,273.

Ricchiazzi, P., S. Yang, C. Gautier, and D. Sowle (1998), SBDART: A research and teaching software tool for plane-parallel radiative transfer in the Earth's atmosphere, Bull. Am. Meteorol. Soc., 79, 2101-2114.

Schmetz, J. (1989), Towards a surface radiation climatology: Retrieval of downward irradiances from satellites, Atmos. Res., 23, 287-321.

Schmetz, J. (1993), Relationship between solar net radiative fluxes at the top of the atmosphere and at the surface, J. Atmos. Sci., 50, 1122-1132.

Sèze, G., and M. Desbois (1987), Cloud cover analysis from satellite imagery using spatial and temporal characteristics of the data, J. Clim. Appl. Meteorol., 26, 287-303.

Shettle, E. P., and R. W. Fenn (1979), Models for the aerosols of the lower atmosphere and the effect of humidity on their optical properties, Environ. Res. Pap. 676, 68 pp., Air Force Geophys. Lab., Hanscom AFB, Mass.

Stackhouse, P. W., S. K. Gupta, S. J. Cox, M. N. Chiacchio, and J. C. Mikovitz (2001), The WCRP/GEWEX Surface Radiation Budget Project release 2: An assessment of surface flux at 1 degree resolution, in IRS2000: Current Problems in Atmospheric Radiation, pp. 485-488, A. Deepak, Hampton, Va.

Stuhlmann, R., M. Rieland, and E. Raschke (1990), An improvement of the IGMK model to derive total and diffuse solar radiation at the surface from satellite data, J. Appl. Meteorol., 29, 586-603.

Tanré, D., C. Deboo, P. Duhaut, M. Herman, J. J. Morcrette, J. Perbos, and P. Y. Deschamps (1986), Simulation of the satellite signal in the solar spectrum, Lab. d'Opt. Atmos., Univ. des Sci. et Tec., Lille, France.

Tarpley, J. D. (1979), Estimating incident solar radiation at the surface from geostationary satellite data, J. Appl. Meteorol., 18, 1172-1181.

Valero, F. P. J., P. Minnis, S. K. Pope, A. Bucholtz, B. C. Bush, D. R. Doelling, W. L. Smith Jr., and X. Dong (2000), Absorption of solar radiation by the atmosphere as determined using satellite, aircraft, and surface data during the Atmospheric Radiation Measurement Enhanced Shortwave Experiment (ARESE), J. Geophys. Res., 105, 4743-4758.

Weinreb, M., M. Jamieson, N. Fulton, Y. Chen, J. X. Johnson, J. Bremer, C. Smith, and J. Baucom (1997), Operational calibration of geostationary operational environment satellite- 8 and -9 imagers and sounders, Appl. Opt., 36, 6895-6904.

Welch, R. M., S. K. Cox, and J. M. Davis (1980), Solar Radiation and Clouds, Meteorol. Monogr., vol. 39, 95 pp., Am. Meteorol. Soc., Boston, Mass.

Whitlock, C. H., T. P. Charlock, W. F. Staylor, R. T. Pinker, I. Laszlo, A. Ohmura, H. Gilgen, T. Konzelman, R. C. Di Pasquale, C. D. Moats, S. R. LeCroy, and N. A. Ritchey (1995), First global WCRP shortwave surface radiation budget dataset, Bull. Am. Meteorol. Soc., 76, 905-922. Wild, M., A. Ohmura, H. Gilgen, and E. Roeckner (1995), Validation of general circulation model radiative fluxes using surface observations, J. Clim., 8, 1309-1324

Zuev, V. E. (1970), Propagation of Visible and Infrared Radiation in the Atmosphere, John Wiley, Hoboken, N. J.

M. J. Bottino, J. C. Ceballos, and J. M. de Souza, Divisão de Satélites e Sistemas Ambientais, Centro de Previsão de Tempo e Estudos Climáticos, Instituto Nacional de Pesquisas Espaciais, Cachoeira Paulista, São Paulo 12630-000, Brazil. (bottino@cptec.inpe.br; ceballos@cptec. inpe.br; jaidete@cptec.inpe.br) 